\title{
Development of Android-Based Specialization Tests for Selection of Prospective Vocational Students
}

\author{
Rina Febriana Hendrawan ${ }^{1, *}$ Muksin Muksin ${ }^{2,}$ Dede Rahmat Hidayat ${ }^{3}$ \\ ${ }^{I}$ Technology and Vocational Education, Universitas Negeri Jakarta, Indonesia \\ ${ }^{2}$ Faculty of Engineering, Universitas Negeri Jakarta, Indonesia \\ ${ }^{3}$ Faculty of Psychology, Universitas Negeri Jakarta, Indonesia \\ *Corresponding author. Email: rinafebriana@unj.ac.id
}

\begin{abstract}
This study aims to develop an android-based vocational student selection specialization instrument to prepare appropriate Vocational Education inputs. Each student has a unique character. Uniqueness is an advantage, and in education, this advantage is called potential, which must be continuously trained and developed. The problem with this unique potential is how the student can appropriately identify this potential. One effort that for identification their potential can make is to conduct an assessment. The advantage of this android-based application is that it is efficient because it does not require duplicate assessment tool. It is interesting because it can do it with instruments with high validity. Several relevant research results conclude that Android applications are quite productive because applications. They can be used and become tools for similar purposes elsewhere. The method used in this research is Research and Development with Decide, Design, Develop, Evaluate (D-D-D-E) models. The define stage identifies the indicators in the instrument of interest. The design stage is to make the overall appearance of the application. The development stage is to design an application with the need for specialization instruments. The evaluation stage measures the ease of reading the device, the clarity of the tool, the use of language, and the clarity of sentences.
\end{abstract}

\section{Keywords: My Interests App, Android, Test Selection, Vocational Students}

\section{INTRODUCTION}

In line with the Government's policy on the Revitalization of Vocational High Schools (SMK) to improve the quality and competitiveness of Indonesian human resources at the secondary education level, efforts have been made for some time, including increasing the number of Vocational High Schools. The human resources are intended to accommodate a more significant number of students participating in vocational education to anticipate various industrial sectors. However, the desire to improve the capacity of human resources technically does not consider the input aspect.

Vocational education is secondary education that prepares students to be able to work in their respective fields. Vocational education is built to form a skilled, competitive, and competent workforce from an early age. So that students who graduate from Vocational High Schools (SMK) are ready to work according to their fields. Labour is human, and every human being has a unique character. Uniqueness is an advantage; in education, this advantage is called potential, which must be continuously trained and developed. The problem that arises is how the issues can appropriately identify this potential. The right way is to do an assessment. A good evaluation will produce accurate information about an individual's uniqueness; however, carrying out a check with high validity and accuracy requires a professional in the field, which cannot be done for large numbers.

For this reason, technology is needed that can assist assessments with a broader reach without reducing the level of assessment accuracy. The use of technology today is unavoidable, and people 
constantly carry out activities related to technology. The use of technology can change the mindset and attitude, or behavior [1].

One of the efforts to meet the principles of assessment in the recruitment and selection system for prospective SMK students must be based on appropriate considerations to meet inputs with fields of interest to students. For this reason, as a first step, it is necessary to develop an assessment instrument to select prospective Vocational Education students. Computer-based tests in this period became common and commonly used for various purposes. Difficulties in learning [2], Rama is even used to determine color blindness [3]. Several competencies need to be updated and added to support students' skills in dealing with the development of work in the industry related to office communications in the 4.0 industrial revolution era to improve the office work effectiveness, such as: 1) information management using social media, web, and online application of goods or services sales, 2) mastery of communication using social media, the web, and online application of goods or services sales, 3) knowledge of international languages.

Widiningrum et al. stated that it is necessary to adjust the competence of office communication between the curriculum and industry to harmonize the learning carried out in schools and technologybased industries. [4]. However, there are still not many computer-based tests or applications as assessment tools. Chapman \& Webster began to use technology to recruit and select employees in the corporate environment [5]. Attali conducted a test by running a test through computer games (games) to measure the performance of employees in the industry [6].

Information technology is a term to define everything or technological equipment that can make it easy for someone to create, change, store or even share information. According to Wikipedia in Indonesian, android is a Linux-based operating system designed for touch screens on mobile devices such as smartphones and tablet computers. The utilization of smartphones that are pretty easy to carry, easily accessible, and affordable as a medium of communication learning will significantly impact students [7]

The use of Android-based learning media is one of the applications of 21 st-century learning styles (Calimag et al.). The use of this kind of learning media can help improve students' academic performance in the form of learning outcomes in the cognitive domain [8] and students' learning motivation ([9]. Smartphones and tablets have the power to transform the learning experience. This type of learning media allows students to learn not limited by time and place with interesting applications [10].

\section{LITERATURE REVIEW}

\subsection{Overview of Vocational High School Students}

Vocational schools play a role in facilitating student development. The developmental tasks of students at the SMK level are closely related to the fulfillment and happiness of their lives. The reality so far shows that there is a tendency for elementary school graduates to enter junior high school (SMP), and junior high school graduates entering high school (SMA) or vocational high school (SMK), and many high schools or vocational high school graduates entering college who have not-based on the direction of the students' specialization that had supported by their potential and adequate selfconditions as capital for optimal potential development, such as basic abilities (intelligence), talents, interests and physical and socio-cultural conditions and their career interests. The students so far choose a high school based on their parents' wishes, economic considerations, and the value of the learning outcomes they have taken. As a result, after being in junior high school and high school or vocational school and college, students often experience learning difficulties, fall into various forbidden behaviors and other personal problems, so they don't go up to grades/levels, change majors/study programs, move education units/colleges, or even drop out of the education unit/college (drop out) [1]

Regulation of the minister of education and cultur, the direction of specialization in Vocational High Schools is specialization in compulsory subjects, a field in areas of expertise and expertise packages (vocational), direction/implementation of careers/jobs, specialization in advanced studies [2]

\subsection{Android App}

Science and technology are also developing rapidly; smartphone devices have dominated daily human life with various facilities provided. Android is an operating system that is widely used in smartphones. Android is an operating system for Linux-based mobile devices that includes an operating system, middleware, and applications. 
Since being bought by Google, Android has experienced speedy growth.

The application comes from the word in the language English is an application which means application, application, or use. According to Hendrayudi (2009: explains that "application is a collection of commands program created to do certain (special) jobs." In terms, the meaning of application is a program that is ready to use made to perform a function for users of application services and other applications that can be used by a target to be addressed. The app has meaning in problemsolving using one of the processing techniques application data that usually races on the desired computation or expected and data processing expected.

One application program that is often used is Android. Android is a Linux-based operating system that is open (open source) and designed for touch screens on mobile devices such as smartphones and tablet computers.

In Indonesia, Android itself is an operating system that attracted a lot of people. Apart from the fact that Android is a open operating system (Open Source), android too classified as an operating system that is cheap, easy and light.

\subsection{Measurement of interest with RIASEC typology}

The specialization scale aims to see the suitability of the choice with the student's interest in one of the skill programs [3]. The most frequently used assessment tool in career planning is the "RIASEC Hexagon". This assessment tool was first introduced in the 1970 s by Dr John L. Holland. Dr Holland suggests six different categories that can describe the relationship between personality characteristics and the work environment. The six categories consist of Realistic, Investigative, Artistic, Social, Enterprising, and Conventional [4].

Based on some of the research results above that technology can be used for the recruitment and selection process, the world of education can also use technology to select new students, especially in vocational/vocational education. The education system recognizes input, process, and output systems. The novelty in this research is developing an androidbased application as a student selection tool as one of the components of the education system, namely the input component, so it is necessary to create a selective assessment for prospective vocational education students. This application can be used directly by students to find their area of interest and help provide recommendations in selecting further studies.

\section{METHOD}

Needs analysis based on preliminary research found that the factors that influence junior high school students in choosing to continue their studies at SMK are the interest factor with a percentage of $74.63 \%$ [5]. This interest factor is then detailed based on the RIASEC specialization theory from Doctor Holland. Product evaluation was carried out by giving questionnaires to respondents regarding the readability of the My Interests app which consisted of a straightforward reading of the instrument, playing the instrument, use of language, and clarity of sentences in the application.

This study adopts the decide, design, develop, evaluate (D-D-D-E) model by Iver and Baron [6]. This development model consists of 4 stages: deciding or setting the goals and contents of the application of interest. The decision stage is the stage for planning multimedia products. In this stage, several steps are: determine project goals, brainstorm content, and conduct research. The design stage is making the program structure. The design stage is the stage of visual thinking because it produces a blueprint for the entire product multimedia in a material outline, layout display, and flowchart.

\begin{tabular}{|c|c|c|c|}
\hline & \multicolumn{2}{|c|}{ Decide } & \\
\hline \multicolumn{2}{|c|}{$\begin{array}{l}\text { Secondary data } \\
\text { retrieval }\end{array}$} & \multicolumn{2}{|c|}{$\begin{array}{l}\text { Primary data } \\
\text { collection }\end{array}$} \\
\hline & \multicolumn{2}{|c|}{ Design } & \\
\hline \multirow[t]{5}{*}{$\begin{array}{l}\text { Create } \\
\text { content } \\
\text { outline } \\
\end{array}$} & $\begin{array}{l}\text { Create flow } \\
\text { charts }\end{array}$ & $\begin{array}{c}\text { Create a } \\
\text { display } \\
\text { design }\end{array}$ & $\begin{array}{c}\text { Creating } \\
\text { Storyboards }\end{array}$ \\
\hline & \multicolumn{2}{|c|}{ Development } & \\
\hline & \multicolumn{2}{|c|}{$\begin{array}{c}\text { Product Creation and } \\
\text { Expert Validation }\end{array}$} & \\
\hline & \multicolumn{2}{|c|}{ Evaluation } & \\
\hline & \multicolumn{2}{|c|}{$\begin{array}{l}\text { Application trials by } \\
\text { respondents }\end{array}$} & \\
\hline
\end{tabular}

Figure 1 My Interests application development design

The development stage is making media elements and creates multimedia displays. In the development 
stage, they are starting to develop a multimedia project to be completed, which includes producing media components such as text, graphics, animation, audio, and video.

The evaluation stage is to examine all the design and development processes. A product review has begun to be developed in this evaluation stage, and material experts and media experts carry out validation. Material experts involve experts with a psychological background to review the contents of the instrument. Media experts are experts with experience in Communication and Information Technology. A total of 88 respondents were involved in finding out how much influence each factor had in selecting further studies. Percentage measurement using the following formula:

$\mathrm{P}=\mathrm{F} / \mathrm{n} \mathrm{x}-100 \%$

\section{P: Percentage \\ F: Frequency of each questionnaire answer \\ $\mathrm{n}$ : The total number of questionnaire answers}

\section{RESULT AND DISCUSSION}

The education system in Indonesia recognizes a system of inputs, processes, and outputs. The novelty in this research is using technology to select students as a component of the education system, namely the input component, so it is necessary to develop a selection assessment for prospective students for vocational education.

Several studies have stated that the use of Android is very high among the public, and it is pretty attractive. (Susanti, n.d.) says that androidbased media has very high acceptance and interest among students. Qumillaila et al.'s research regarding the development of the Android version of the AR application states that the android application is effective in helping the learning process.

The development of an android-based application of my interest by adopting the DDDE model had described as follows: the decide stage serves to determine and define the needs in the application development process of my claim. The result of the definition stage is the grid needed to classify the types of interest by adopting the RIASEC specialization type from Dr. John L. Holland..RIASEC is a description of the personality types described in occupational theory. RIASEC's 6 Skill Types, Realistic-Investigative-Artistic-SocialEnterprising-Conventional.
A realistic is a person who likes work activities included in practice and attempts to solve problems directly. An Investigative is a person who likes work related to ideas and thoughts rather than physical work. Artistic is an artistic person who likes activities associated with the creative side of shapes, designs, and patterns. A Social is a social person who likes work that helps others and supports self-development and learning. Enterprising is a person who is like an entrepreneur who wants work related to starting and doing projects, especially businesses. Conventional is a conventional person who likes activities that follow procedures and are routine

The design stage is a process in the initial design to create content in the application of my interest. The following table is the design content of the application in the form of statement items which are indicators of each type of RIASEC. The development stage assesses the content and appearance of the application of my interest, which experts validate. Psychologists carried out the validation of application content, and media experts carried out application validation. This assessment aims to get suggestions for improving the application of my interests in terms of content and appearance of the application.

The following is the design draft to make the display design of the specialization instrument android application. This application is named the My Interests application. The following is the display design of the My Interests application.

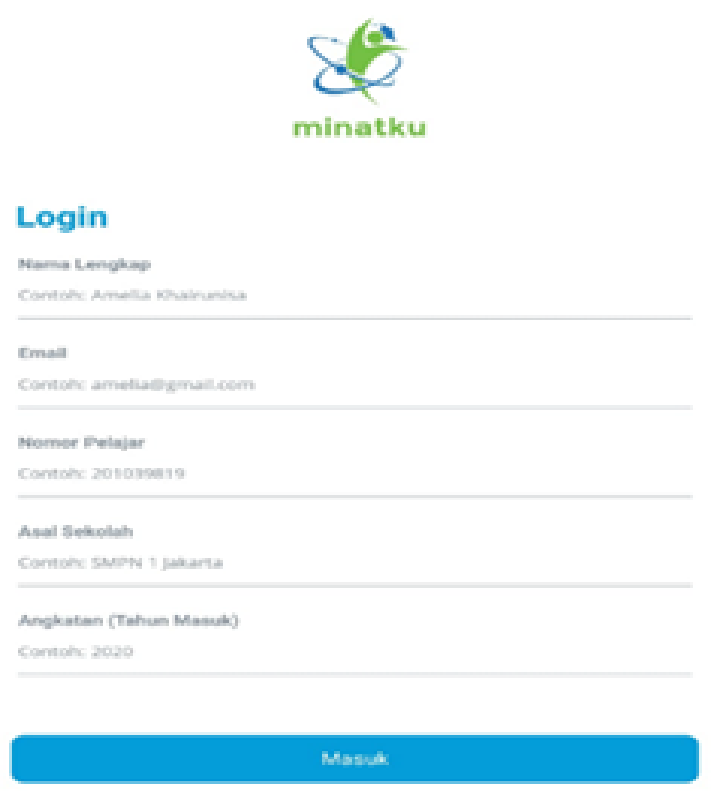

Figure 2 My interest app face view 
After students fill in all the items of the specialization instrument statement, the final result will display the following image:

The evaluation stage aims to review the design app developed to check for completeness and suitability item of interest. The design you want to be made ready for review and validated by material and media experts before testing it on students in the learning process. This specialization application has been through trials. The trial used indicators of ease of reading the instrument, clarity of the device, use of language, and clarity of sentences. The following is a descriptive analysis of the test results:

Table 1. Descriptive statistics

\begin{tabular}{|c|c|c|c|c|c|}
\hline Indicator & N Analysis & N Missing & Mean & Standard Deviation & SE of Mean \\
\hline Ease of reading & 88 & 0 & 3.18 & 0.51 & 0.05 \\
& & & & & \\
\hline Instrument clarity & 88 & 0 & 3.20 & 0.62 & 0.06 \\
\hline Language use & 88 & 0 & 3.25 & 0.48 & 0.05 \\
\hline Sentence clarity & 88 & 0 & 3.28 & 0.50 & 0.05 \\
\hline
\end{tabular}

The test results for the application of my interest get results for the indicator of ease of reading. The average score of the instrument is 3.18, the clarity of the device is the average score of 3.2 , the use of language is 3.25 , and the clarity of the sentence is 3.28. The standard deviation is a reflection of the average variation of the data from the mean. The standard deviation can describe how much the data varies. If the normal deviation value is greater than the mean value, the mean value is a poor representation of the overall data. However, if the average deviation value is smaller than the mean value, the mean value can represent the entire data. The data processing results indicate that all indicators have met the criteria that are good or feasible to use for questions on the application of my interest.

The overall average rating of this application is 3.22 , and if it had converted to a percentage where the highest score is four, then it is at a score of 80.75 with a decent category.

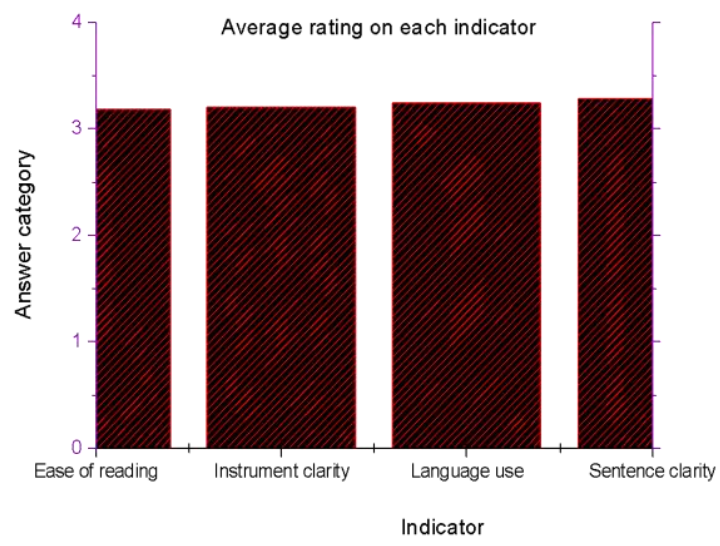

Figure 3 Average rating of each indicator
The overall average rating of this application is 3.22 , and if it had converted to a percentage where the highest score is four, then it is at a score of 80.75 with a decent category. The following is the distribution of the mean value on the data obtained from the sum of the total data for each indicator:

\section{CONCLUSION}

Results of data analysis concluded that the development of an Android-based selective assessment instrument application to select prospective vocational students was appropriate to be used. It can be used as a medium to provide recommendations to junior high school students in the selection of further studies.

The implication of this specialization application is to conduct a self-assessment of student interests based on the theory of specialization. A good assessment will produce accurate information about the unique profile of an individual. Thus, to meet the above principles, the recruitment and selection system for prospective SMK students must be based on an appropriate assessment to ensure the school's suitability with the input to be addressed.

\section{AUTHORS' CONTRIBUTIONS}

The author contributes in improving the quality of input for prospective vocational students according to their specialization.

\section{ACKNOWLEDGMENTS}

This work was supported by Lembaga Penelitian dan Pengabdian Masyarakat (LPPM), Universitas 
Negeri Jakarta, under Grant Number: 5/PPI/LPPM/IV/2021, April 26, 2021.

\section{REFERENCES}

[1] Destiana, "The influence of android-based information technology (Smartphone) in industry 4.0 education," Pros. Semin. Nas. Educator. program. Postgraduate. Univ. pgri palembang, 2019, pp. 190-197. Available: https://jurnal.univpgri-

palembang.ac.id/index.php/Prosidingpps/article/ view/2528

[2] C. U. Mata, P. Fisika, Z. Z. Rendy, F. Bakri, A. H. Permana, and D. Muliyati, "Computer Based Test Software Development SNF2015-III-23 SNF2015-III-24," vol. IV, 2015, pp. 23-30. Available:

http://journal.unj.ac.id/unj/index.php/prosidings nf/article/view/5015

[3] D. F. Racma, "Designing a Computer-Based Self-Evaluation Using a Randomized Question Bank Method on Computer Network Materials Using Actionscript 2.0," vol. 4, no. 4, 2015, pp. 14-23.

DOI: https://doi.org/10.33488/1.ma.2017.1.72

[4] R. Widianingrum, S. Aw, F. Y. Hermanto, and M. Sholikah, "Office Communication Competencies for Vocational High School in Industri 4.0," Din. Pendidik., vol. 15, no. 1, 2020, pp. 77-86. DOI: https://doi.org/10.15294/dp.v15i1.24348

[5] D. S. Chapman and J. Webster, "The use of technologies in the recruiting, screening, and selection processes for job candidates," Int. J. Sel. Assess., vol. 11, no. 2-3, 2003. pp. 113120. DOI: https://doi.org/10.1111/14682389.00234

[6] Y. Attali and M. Arieli-Attali, "Gamification in assessment: Do points affect test performance?," Comput. Educ., vol. 83, 2015. pp. 57-63. DOI: https://doi.org/10.1016/j.compedu.2014.12.012

[7] D. Kim, D. Rueckert, D. Kim, and D. Seo, "Students 'Perceptions and Experiences of," Lang. Learn. Technol., vol. 17, no. 3, pp. 5273, $2012 . \quad$ Available: https://scholarspace.manoa.hawaii.edu/bitstrea m/10125/44339/1/17_03_kimetal.pdf

[8] K. K. Jabbour, "An analysis of the effect of mobile learning on lebanese higher education," Informatics Educ., vol. 13, no. 1, 2014. pp. 115.

DOI: https://doi.org/10.15388/infedu.2014.01

[9] J. Nealbert, V. Calimag, A. G. Miguel, R. S. Conde, and L. B. Aquino, "14. Eng-Ubiquitous Learning Environment Using Android-Luisa B. Aquino," Int. J. Res. Eng. Technol., vol. 2, no. 2, 2014. pp. 2321-8843. DOI: https://doi.org/10.24176/jpp.v3i2.5859

[10] K. Squire, "Mobile media learning: Multiplicities of place," Horiz., vol. 17, no. 1, 2009. pp. 70-80, 2009. DOI: https://doi.org/10.1108/10748120910936162

[11] D. J. P. D. D. M. kementerian P. D. Kebudayaan, "Interest and Cross Interest Model t,” pp. 1-24, 2017. Available: https://eprints.umm.ac.id/75078/1/SEKA.pdf

[12] Permendikbud, "Permen No 64 Tahun 2014 About Interest in Secondary Education," Minister of Education. and Culture of the Republic of Indonesia., 2014.

[13] S. T. Hidajat, "Interest Scales For Vocational High School Student Of SMKN 3 Bengkulu City," vol. 15, no. 2, 2016, pp. 58-71. DOI: https://doi.org/10.33369/triadik.v15i2.2868

[14] R. Farida and A. Hudiyah Bil Haq, "Vocational Interest Scale: Strategies to Recognize Students' Vocational Interests," 2017, pp. 553-562. DOI: 10.1088/1742-6596/1807/1/012014

[15] R. Febriana and D. R. Hidayat, "Identification Of Factors Affecting First Middle School Students ( Smp ) In Choosing Further Studies To Vocational High School ( Vocational School ) In Jakarta., 2020. Unpublished.

[16] W. Budi et al., "Development Of Computer Assisted Instruction (Cai) Media In 3 Dimensional Animation Lessons "Creating 3 Dimensional Animation Characters" To Improve Learning Outcome Of Class Xi Students Department Of Multimedia at SMK Mahardika Surabaya", 2016. pp. 1-5. Available: https://docplayer.info/88385388Pengembangan-media-computer-assistedinstruction.html 